\title{
Bile acid, neutral sterol and faecal fat excretion in subjects treated with fenfluramine and its relationship to fenfluramine-induced diarrhoea
}

\author{
M. S. SIAN \\ B.Sc. \\ A. J. Harding Rains \\ M.S., F.R.C.S.

\section{Professorial Department of Surgery, Charing Cross Hospital Medical School, Fulham Palace Road, London W6 8RF}

\begin{abstract}
Summary
Bile acid, neutral sterol and faecal fat excretion was studied over a period of 9 weeks in a group of 16 healthy subjects before, during and after administration of fenfluramine. Statistical analysis revealed a significant increase in bile acid excretion during the drug phase $(P<0.02)$; and during recovery period of 3 weeks $(P<0.05)$. Faecal neutral sterol, as the total of coprostanol and cholesterol elimination was also enhanced after fenfluramine. Coprostanol was replaced by cholesterol in 12 subjects. Faecal fat was studied in 6 subjects, the excretion increased during the drug phase $(P<0.05)$, and remained elevated during the post-drug period $(P<0.01)$. The composition of the bile acids remained unaltered in all the subjects except 3 who had a fenfluramine-induced watery diarrhoea; and these excreted chenodeoxy and cholic together with smaller amounts of secondary bile acids. A higher excretion of bile acids was found in the 8 overweight subjects $(P<0.01)$ before ministration of fenfluramine.

These results are discussed in an attempt to correlate the effect of fenfluramine with changes in bile acid and neutral sterol excretion, and its relationship to fenfluramine-induced diarrhoea.
\end{abstract}

\section{Introduction}

Obesity presents a major nutritional and medical problem. Its complications are well documented such as increased morbidity and mortality due to cardiovascular disorders, hypertension, diabetes and cholelithiasis. Dietary restriction on its own by personal effort is not always effective in the management of simple, exogenous obesity. Controlled trials on the use of appetite suppressants such as amphetamines have shown a variety of undesirable side effects including central nervous stimulation, addiction, toxicity, euphoria and even ineffectiveness. The use of amphetamines has been discouraged but fenfluramine, an analogue of amphetamine, has become widely used as an anti-obesity agent devoid of central nervous stimulation (Munro, Seaton and Duncan, 1966; Le Douarec and Niven, 1970). There are reports of its beneficial effects on hyperlipidaemia (Pawan, 1969; Bliss, Kirk and Newall, 1972), on hypercholesterolaemia (Tomlinson, Lines and Greenfield, 1975), and on hyperglycaemia (Turtle, 1972). However it has been reported that some patients on the drug complain of frequency of bowel motions amounting to diarrhoea. The incidence of diarrhoea reported by Munro et al. (1966), Hollingsworth and Amatruda (1969) and Sedgwick (1972) was 40,44 and $67 \%$ respectively. The cause of this diarrhoea consecutive to the treatment with fenfluramine is obscure. No direct correlation has been reported between the onset of diarrhoea and serum levels of fenfluramine. Dietetic survey in people with frequency of bowel motions suggest an interaction between nutrients (fish) and the drug. Studies by Duhault and Verdavainne (1967) suggested that diarrhoea may be related to the decreased absorption of triglycerides in the intestinal tract, to the release of serotonin or to the alteration in gut motility. Some of these views were supported by Garattini (1971) who reported that the lipidlowering effect of fenfluramine was related to the inhibition exerted by the drug on gastric and intestinal motility. In another study Dannenburg and Ward (1971) demonstrated that, in vitro, fenfluramine inhibited pancreatic lipase and they suggested that this reduces the intestinal absorption of fat. But fat balance studies carried out by Evans et al. (1975) revealed that the apparent digestibility of fat in healthy students was unimpaired, and there was no evidence of reduction of intestinal fat absorption.

One line of study which interests the present authors is the examination of the effect of fenfluramine on bile acid metabolism, and in this investigation they set out to eximine the effect of fenfluramine on total faecal bile acid and neutral sterol excretion in healthy subjects before, during and after administration of fenfluramine and to evaluate the changes in bile acid excretion to fenfluramineinduced diarrhoea. The second purpose of the study was to examine the effect of fenfluramine on the 
composition of faecal bile acids and neutral sterols excreted by the subjects before and after a course of fenfluramine.

\section{Subjects, experimental design and methods}

\section{Subjects}

Sixteen healthy subjects who were members of the hospital staff kindly participated in the study.

\section{Design of study}

The study was conducted over a period of 9 weeks, consisting of 3 consecutive periods of 3 weeks in the sequence of: 1 pre-drug, 2 drug, 3 post-drug. Each subject was his or her own control to minimize intersubject variation. In an attempt to eliminate the influence of dietary change, all subjects were asked to make no deliberate alteration in their diet. The subjects were seen once a week when they were supplied with tablets for the following week.

After an initial pre-drug period, oral fenfluramine was instituted at a dose of $40 \mathrm{mg} /$ day in the first week, $60-80 \mathrm{mg} /$ day in the second week, and reduced to $40 \mathrm{mg} /$ day during the third week before stopping.

In order to observe the pattern of faecal bile acid excretion in the overweight individuals as compared to subjects of normal weight, the 16 subjects were divided into 2 groups. Eight subjects were within $10 \%$ of their ideal body weight for age, sex and height according to the Statistical Bulletin (1959). Eight subjects were between 11 and $80 \%$ above their ideal body weight.

\section{Analytical methods \\ Collection and processing of faeces}

Total stool collections were made over 3-day periods in 6 subjects during the 3 phases of the study. The remaining 10 subjects collected faeces from one day at a time and provided 9 collections over the study period. Faeces were collected into plastic containers and stored at $-20^{\circ} \mathrm{C}$ until analysed. Before analysis the stool was thawed and homogenized. A $50-\mathrm{g}$ aliquot was freeze-dried for all analyses.

\section{Faecal fat analysis}

Faecal fat was analysed for the subjects with 3-day stool collections by the method of Van de Kamer, Huinink and Weijers (1949). Freeze-dried faeces were used because it has been shown that such samples yield more consistent results (Weijers and Van de Kamer, 1953).

\section{Analysis of bile acids and neutral sterols}

The freeze-dried samples of faeces were extracted using a method based on that of Evrard and Janssen
(1968), with subsequent analysis of bile acids and neutral sterols by gas chromatography (Eneroth, Hellstrom and Sjovall, 1968). The degree of conjugation of bile acids was determined using thin layer chromatography (Huang and Nichols, 1975).

\section{Statistical analysis}

Student's $t$-test was used to compare the bile acid and neutral sterol excretion in the 16 subjects during the 3 phases of the study.

The reproducibility of bile acid analysis was studied in one individual over the 9-week experimental period. The coefficient of variation of replicate analysis $(n=15)$ was $7.6 \%$ during the predrug period. The mean faecal bile acid excretion during this period was $9 \cdot 3 \pm 0.4 \mathrm{mg} / \mathrm{g}$ dry weight faeces (range 8.9-9.9). After the administration of the drug the coefficient of variation was $9.8 \%$ and the mean bile acid excretion was $11 \cdot 0 \pm 0.5 \mathrm{mg} / \mathrm{g}$ dry weight faeces (range 10·3-11·7).

\section{Results \\ Bile acids}

The mean bile acid excretion for the 16 subjects during the pre-drug period was $9 \cdot 3 \pm 3 \cdot 1 \mathrm{mg} / \mathrm{g}$ dry weight faeces compared to $12 \cdot 1 \pm 4 \cdot 5 \mathrm{mg} / \mathrm{g}$ dry weight during the drug period $(P<0.02)$. The bile acid excretion remained elevated after the withdrawal of fenfluramine $(11.6 \pm 3.4 \mathrm{mg} / \mathrm{g}$ dry weight) $(P<0.05)$. There was no statistically significant difference between the excretion during the drug phase and the post-drug phase $(12.1 \pm 4.5 \mathrm{mg} / \mathrm{g}$ dry weight compared to $11.6 \pm 3.4 \mathrm{mg} / \mathrm{g}$ dry weight). This implies that the drug effect persisted for at least 3 weeks after the withdrawal of fenfluramine.

Bile acid excretion in the subjects with normal body weight (Fig. 1a) was compared with the excretion in the overweight subjects (Fig. 1b). During the period before the administration of fenfluramine the bile acid excretion in the overweight subjects $(10 \cdot 8 \pm 3.8 \mathrm{mg} / \mathrm{g}$ dry weight $)$ is significantly higher $(P<0.01)$ than the bile acid excretion in those of normal weight $(7.7 \pm 0.7 \mathrm{mg} / \mathrm{g}$ dry weight). The excretion remained high in the overweight subjects $(13 \cdot 7 \pm 5 \cdot 3$ compared to $10.5 \pm 3.1 \mathrm{mg} / \mathrm{g}$ dry weight) during the drug period $(P<0.01)$; and also during the post-drug period $(12.9 \pm 3.8 \mathrm{mg} / \mathrm{g}$ dry weight compared to $10.3 \pm 2.6 \mathrm{mg} / \mathrm{g}$ dry weight $; P<0.01)$.

In 7 subjects bile acid excretion reached a peak by the end of the second week on the drug. In 4 subjects excretion dropped during the first week and then increased in the second and third week of medication. Three subjects had diarrhoea, and limited quantitative data only were obtainable because of the problem of 24-hr faecal collection in these subjects. 
(a)

$\left.\begin{array}{l}\text { Bile acids } \\ \square \quad \text { Neutral sterols }\end{array}\right\} \begin{aligned} & \text { Total faecal } \\ & \text { steroids }\end{aligned}$

Dry wt faeces (mg/g)

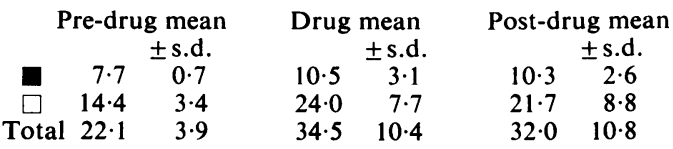

Level of significance $(P)<0.01$ (pre- v. drug mean) $<0.01$ (pre- v. post-drug mean)

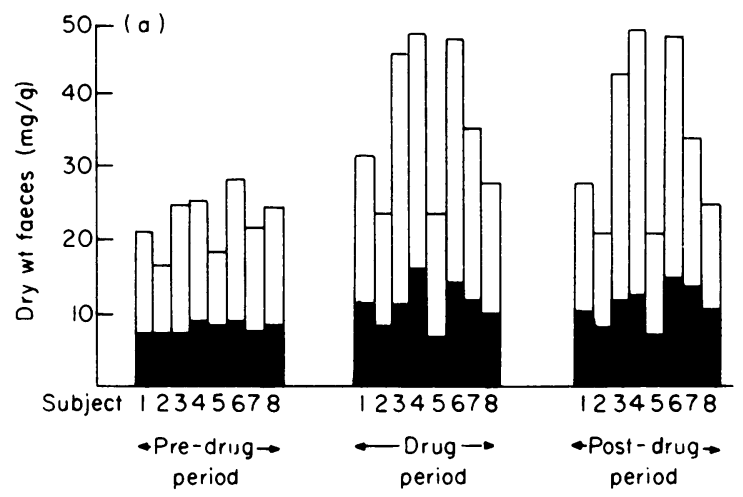

(b)

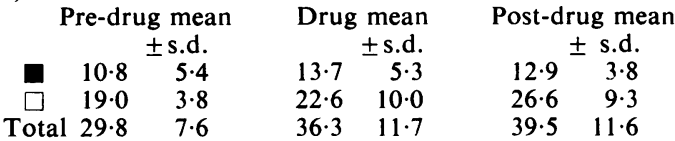

Level of significance $(P)<0.02$ (pre- v. drug mean) $<0.01$ (pre- v. post drug mean)

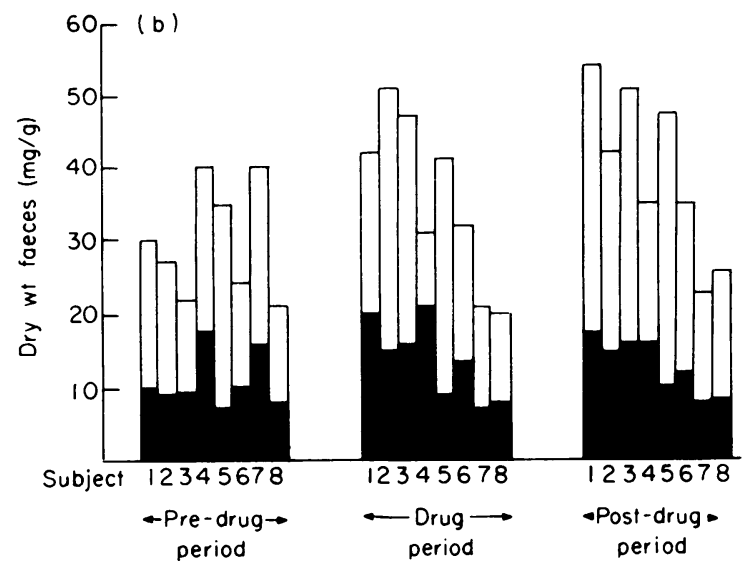

Fig. 1. (a) Total faecal steroid excretion during 3 phases of the study in 8 subjects with weights within $10 \%$ of ideal body weight.

(b) Total faecal steroid excretion during 3 phases of the study in 8 subjects overweight between 10 and $80 \%$ above ideal body weight.

\section{Neutral sterols}

The neutral sterol excretion, as the total of coprostanol and cholesterol, also indicated a similar increase. The mean neutral sterol excretion for the 16 subjects was $16.7 \pm 4.9 \mathrm{mg} / \mathrm{g}$ dry weight during the pre-drug period. The excretion increased to $23.3 \pm 8.6 \mathrm{mg} / \mathrm{g}$ dry weight during the drug period $(P<0.02)$. The excretion remained elevated at $24.1 \pm 9.0 \mathrm{mg} / \mathrm{g}$ dry weight during the post-drug period $(P<0.01)$.

Total faecal steroids (bile acids and neutral sterols)

The mean excretion of total faecal steroids as the sum of bile acids and neutral sterols was $26.0 \pm 7.0 \mathrm{mg} / \mathrm{g}$ dry weight during the pre-drug period. The excretion increased to $35 \cdot 2 \pm 10 \cdot 7 \mathrm{mg} / \mathrm{g}$ dry weight during the drug period $(P<0.01)$, and to $36.7 \pm 11.5 \mathrm{mg} / \mathrm{g}$ dry weight during the post-drug period ( $P<0.01)$ (Fig. 1a and $b$ ).

The excretion of total faecal steroids in the overweight subjects was $29.8 \pm 7.6 \mathrm{mg} / \mathrm{g}$ dry weight as compared with $22 \cdot 1 \pm 3.9 \mathrm{mg} / \mathrm{g}$ dry weight in the subjects of normal weight. This failed to reach the $5 \%$ level of significance.

\section{Faecal fat}

The mean faecal fat excretion in 6 subjects duringo the pre-drug period was $2.61 \pm 0.39 \mathrm{~g} /$ day. There was a significant increase in the excretion during theo drug period $(3.86 \pm 1.09 \mathrm{~g} /$ day $; P<0.05)$ : and also during the post-drug period $(3.14 \pm 0.46 \mathrm{~g} /$ day; $P<0.01$ ), (Fig. 2).

Qualitative analysis of faecal bile acids and neutral sterols

Bile acids

The qualitative composition of faecal bile acids in the subjects without diarrhoea remained basically unaltered. The major components were secondary bile acids lithocholic, isolithocholic, deoxycholic and smaller quantities of other dihydroxy bile acids and bacterial oxidation products as shown in Table 1.

The subjects with fenfluramine-induced diarrhoea excreted increased amounts of primary bile acids, i.e. chenodeoxycholic $(3 \alpha, 7 \alpha)$ and cholic acid (Tri-OH) (Fig. 3). In these subjects the excretion of primary bile acids increased from $2.8 \pm 1.5 \mathrm{mg} / \mathrm{g}$ dry weight, during the pariod before the administration of fenfluramine, to $7 \cdot 3 \pm 5 \cdot 6 \mathrm{mg} / \mathrm{g}$ dry weight during the drug period $(P<0.05)$.

Thin layer chromatography of faecal bile acids revealed that bile acids excreted before and after the administration of fenfluramine were in the unconjugated form (Fig. 4). However, if there were conjugated bile acids in the faeces, these would be present in quantities less than $1 \mathrm{mg} / 100 \mathrm{~g}$ wet faeces 


$\begin{array}{llll}\text { Mean } & 2.61 \mathrm{~g} / \text { day } & 3.86 \mathrm{~g} / \text { day } & 3.14 \mathrm{~g} / \text { day } \\ \text { s.d. } & 0.39 & 1.09 & 0.46 \\ P & <0.05 & \text { (pre- v. drug) } & <0.01 \text { (pre- v. } \\ & & & \text { post-drug) }\end{array}$

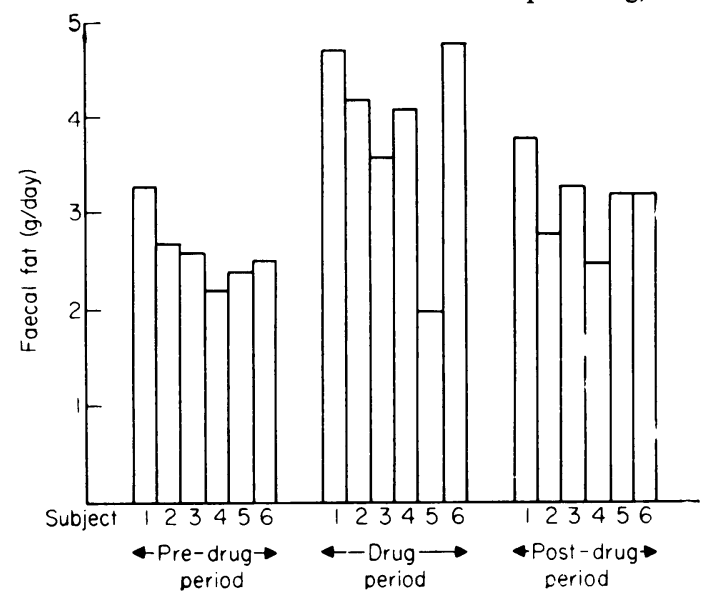

FIG. 2. Faecal fat excretion in 6 subjects during the 3 phases of the study. Faecal fat during the pre-drug period differs significantly from the drug period $(P<0.05)$ and from the post-drug period $(P<0.01)$.

if the sensitivity of the TLC system is taken into consideration.

\section{Neutral sterols}

The analysis of faecal neutral sterols revealed that coprostanol was the major neutral sterol excreted during the pre-drug period (Fig. 5). The pattern of neutral sterols excreted was markedly altered during the drug period. Coprostanol was replaced by cholesterol which then became the predominant sterol in the faeces of the 12 subjects. Cholesterol elimination in the faeces was prolonged in 3 subjects with fenfluramine-induced diarrhoea.

\section{Discussion \\ Alterations in total faecal steroid patterns}

In the present study, the authors have attempted to correlate the effect of fenfluramine with changes in total faecal steroids, individual bile acids and neutral sterol excretion. Results of the study reveal an increased elimination of faecal bile acids after fenfluramine, which coincides with elevated excretion of neutral sterols and faecil fat.

The pattern of faecal bile acid excretion in the subjects without fenfluramine-induced diarrhoea consisted mainly of deoxycholic, lithocholic and isolithocholic acids. These are secondary bile acids present in normal faeces and are produced in the gastrointestinal tract as a result of bacterial degradation of primary bile acids (Hill and Drasar, 1968). The primary bile acids are composed of chenodeoxycholic and cholic acid derived from cholesterol metabolism in the liver.

The pattern of bile acid excretion in the subjects with fenfluramine-induced diarrhoea consisted mainly of primary bile acids with smaller amounts of secondary bile acids (Fig. 3) and cholesterol replacing coprostanol. Studies by Rubulis, Rubert and Faloon (1970) revealed similar observations and reported an increased excretion of primary bile acids, cholesterol and faecal fat in patients treated with antibiotics. They suggested that the replacement of secondary bile acids by primary bile acids and the appearance of cholesterol in place of coprostanol may simply reflect increased transit through the bowel with less exposure of bile acids and cholesterol to bacterial action. Similar findings were also reported by Mitchell and Eastwood (1972) in patients with ileal dysfunction.

Studies carried out by Kirwan et al. (1975) have demonstrated a direct relationship between the colonic motility and faecal bile acid excretion. They reported chenodeoxycholic to be the principal factor

TABLE 1. Qualitative analysis of faecal bile acids in subjects treated with fenfluramine

$\begin{array}{ll}++ & + \\ ++ & + \\ + & + \\ + & + \\ ++ & + \\ \text { trace } & + \\ \text { trace } & ++ \\ \text { trace } & + \\ \text { trace } & \text { trace } \\ \text { trace } & \text { trace } \\ \text { trace } & ++\end{array}$

'trace' represents a GC peak of $<4 \%$ full scale deflection on GC recorder.

+ represents a GC peak of $4-20 \%$ full scale deflection on GC recorder.

++ represents a GC peak of $>20 \%$ full scale deflection on GC recorder. 


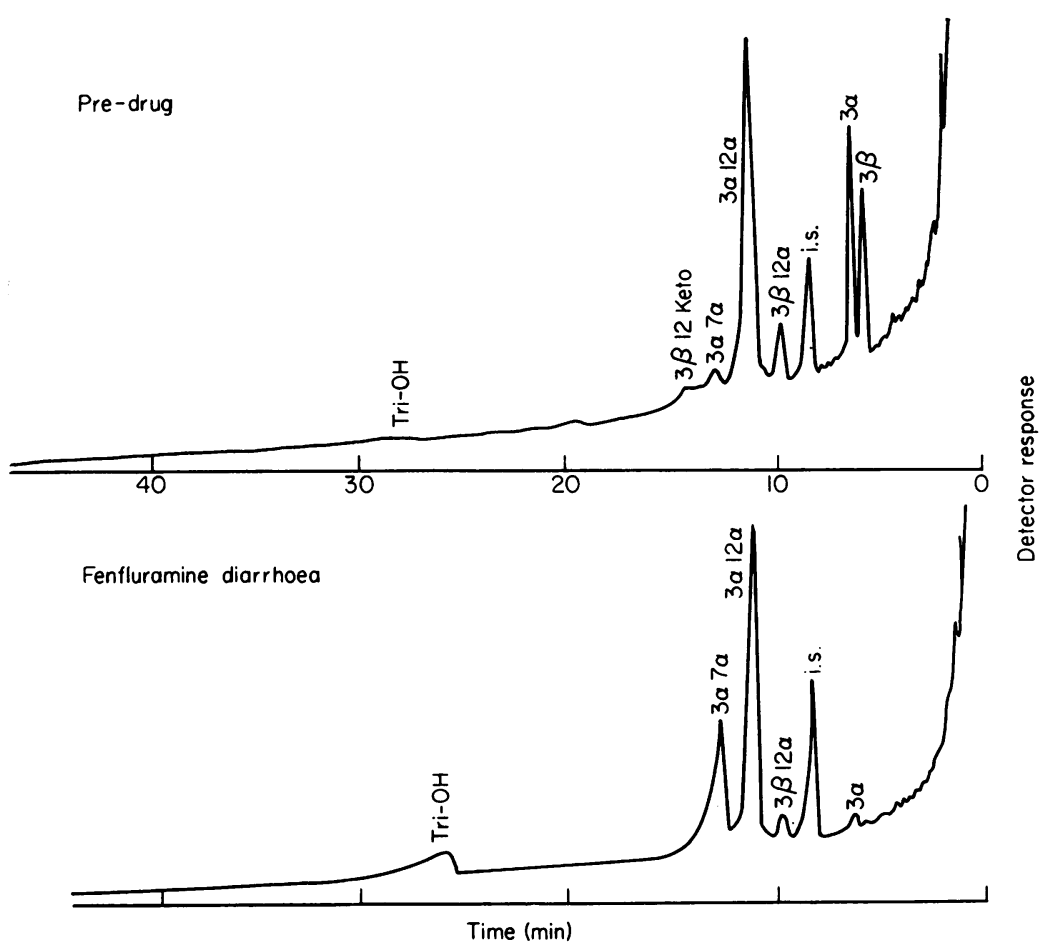

FIG. 3. Gas chromatographic separation of bile acids as methyl esters. Peak identification of main bile acids: secondary bile acids, $3 \beta=$ isolithocholic; $3 \alpha=$ lithocholic; $3 \beta$, $12 \alpha=$ dihydroxy bile acid; $3 \alpha, 12 \alpha=$ deoxycholic. Primary bile acids: $3 \alpha, 7 \alpha=$ chenodeoxycholic; tri-OH = cholic; i.s.=internal standard (23-nor deoxycholic). During the pre-drug period secondary bile acids are predominant in the faeces. During the period of fenfluramine-induced diarrhoea the excretion of primary bile acids increases $(P<0.05)$.

responsible for the changes in motility. In perfusion studies of the human colon Mekhjian, Phillips and Hofmann (1971) demonstrated that chenodeoxycholic was a potent inhibitor of water and electrolytes from the colon and had a greater effect on diarrhoea.

The pattern of neutral sterols in the faeces was altered after the administration of fenfluramine. Normally coprostanol is the predominant neutral sterol with small amounts of cholestanol and plant sterols. These neutral sterols are metabolites formed from cholesterol in the gastrointestinal tract by the action of intestinal micro-organisms (Eneroth, Hellstrom and Ryhage, 1964). These metabolites are poorly absorbed from the gut and, therefore, constitute major neutral sterols in normal faeces. This form of pattern of neutral sterols was observed in the present study during the pre-drug period. After the administration of fenfluramine the excretion of coprostanol was replaced by cholesterol in the faeces (Fig. 5). Similar observation was made by Meihoff and Kern (1968) in patients with mannitol-induced diarrhoea. They reported a decrease in intestinal transit from a mean of $26 \mathrm{hr}$ before the study to $4.6 \mathrm{hr}$ during the period of diarrhoea and demonstrated alterations in faecal steroid patterns together with an increase in bile acids, neutral sterols and faecal fat excretion in their subjects. They suggested that rapid transit through the gastrointestinal tract was the major factor which decreases the normal absorption of bile acids, neutral sterols and faecal fat, hence the excretion of these increases.

Bile acid excretion pattern in the overweight subjects

Bile acid excretion was significantly higher in the overweight subjects. This observation is in agreement with the findings of Miettinen (1971) who reported a higher bile acid and neutral sterol excretion in obese normolipidaemic subjects as compared to non-obese normolipidaemic subjects and demonstrated that the greater the body weight the higher was the excretion of bile acids and neutral sterols. 


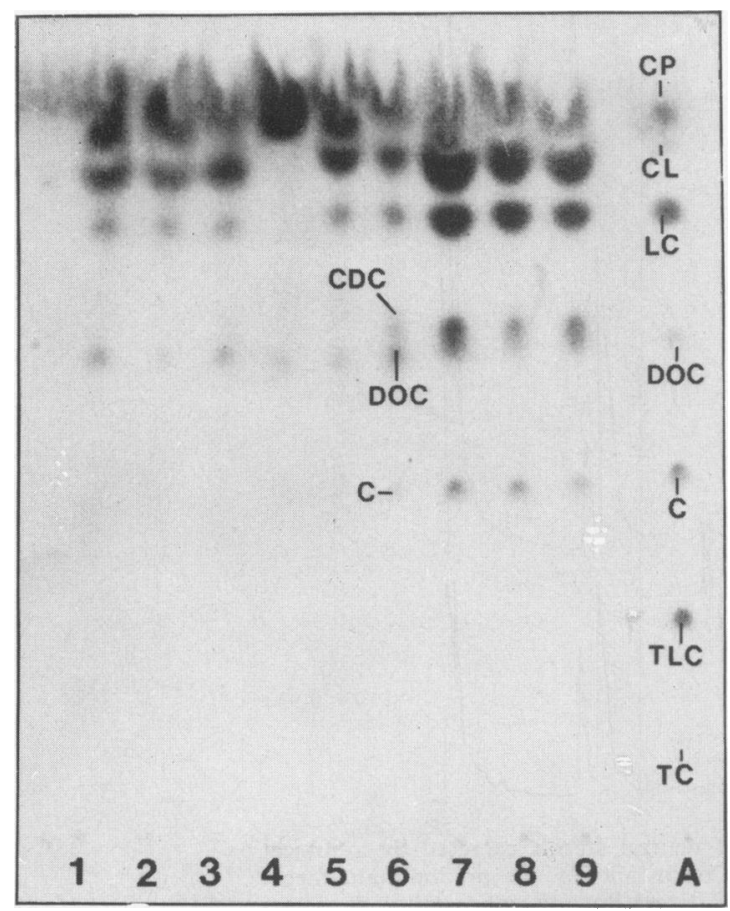

Fig. 4. Thin layer chromatographic separation of faecal bile acids in a subject without fenfluramineinduced diarrhoea. For TLC conditions see text. $A=$ authentic bile acids and neutral sterols. $\mathbf{T C}=$ taurocholic; TLC $=$ taurolithocholic; $L C=$ lithocholic; $\mathbf{C L}=$ cholesterol; $\mathbf{C P}=$ coprostanol. Primary bile acids are not detected in the pre-drug faecal samples (1, 2 and 3) but are detected in samples (5 and 6 ) during the drug period and also during the post-drug period $(7,8$ and 9$)$.

The value of $7 \cdot 7 \pm 0.7 \mathrm{mg} / \mathrm{g}$ dry weight for bile acid excretion in the subjects with normal weight is similar to that of $6.13 \mathrm{mg} / \mathrm{g}$ dry weight for 20 subjects reported by Aries et al. (1971) and that of $8.72 \mathrm{mg} / \mathrm{g}$ dry weight for 5 normals reported by Evrard and Janssen (1968). Similar observations were also reported by Nestel and Hunter (1974) in studies of bile acid excretion in the overweight.

The pattern of bile acid excretion in the overweight subjects compared to those of normal weight differed only in the levels of cholic acid excretion. This was $5 \%$ by weight of the bile acid excretion in the over-weight group compared with $2 \%$ in the normal group $(P<0.05)$.

Bile acid and neutral sterol excretion (cholesterollowering effect)

Results of the present study reveal a significant increase in excretion of bile acids, neutral sterols and faecal fat after fenfluramine. In studies of cholesterol production in obesity Miettinen (1971) reported a direct relationship between body weight and serum cholesterol and faecal excretion of bile acids and neutral sterols. In later studies using the sterol balance technique Miettinen (1973) also reported that the removal of cholesterol as bile acids in the faeces is the primary factor which determines the level of serum cholesterol. Rubulis et al. (1970) studied the effect of neomycin and colchicine on serum cholesterol and reported an increase in excretion of bile acids, neutral sterols and faecal fat. Coincident with these changes there was a significant decrease in serum cholesterol and lipids. Therefore the observation of increased excretion of bile acids and neutral sterols after fenfluramine suggests an increased catabolism of cholesterol and possibly a decrease in the level of serum cholesterol pool.

The lipid-lowering effect of fenfluramine has been reported to be related to the inhibition exerted by the drug on gastric and intestinal motility (Garattini, 1971). The lipid-lowering effect of the drug is of particular interest in the obese patient where endogenous production of cholesterol is normally increased (Miettinen, 1971). The present results are consistent with the previous observation made from this laboratory, that fenfluramine caused a small but significant decrease in serum cholesterol (Bliss et al., 1972). The cholesterol-lowering effect of fenfluramine was also observed by Dannenburg and Chremos (1971), and by Tomlinson et al. (1975) who also reported a decrease of $14 \%$ in the level of serum cholesterol in hypercholesterolaemic patients within 2 weeks.

From their study it appears to the authors that the increased faecal bile acid and neutral sterol excretion observed after administration of fenfluramine suggests enhanced removal of cholesterol. This could be beneficial in obesity and related metabolic disorders.

\section{Acknowledgments}

This work has been supported in part by Servier Laboratories who also supplied the fenfluramine used in this study. We are grateful to Dr J. Swale, Dr D. I. Rees and Mr C. J. C. Kirk for technical advice. Sincere thanks are also due to Mr S. Ganley for illustrations, to Dr K. D. Macrae for statistical analysis and to Mrs C. Hiscoke for typing the manuscript.

\section{References}

Aries, V.C., Crowther, J.S., Drasar, B.S., Hill, M.J. \& ELLIS, F.R. (1971) The effect of a strict vegetarian diet on the faecal flora and faecal steroid concentration. Journal of Pathology, 103, 54.

Bliss, B.P., KirK, C.J.C. \& Newall, R.G. (1972) Effect of fenfluramine on glucose tolerance, insulin, lipid and lipoprotein levels in patients with peripheral arterial disease. Postgraduate Medical Journal, 48, 409.

Dannenburg. W.N. \& Chremos, A.N. (1971) Plasma lipids and weight changes of obese treated with fenfluramine. Diabetes, 20 (Suppl. 1), 351. 


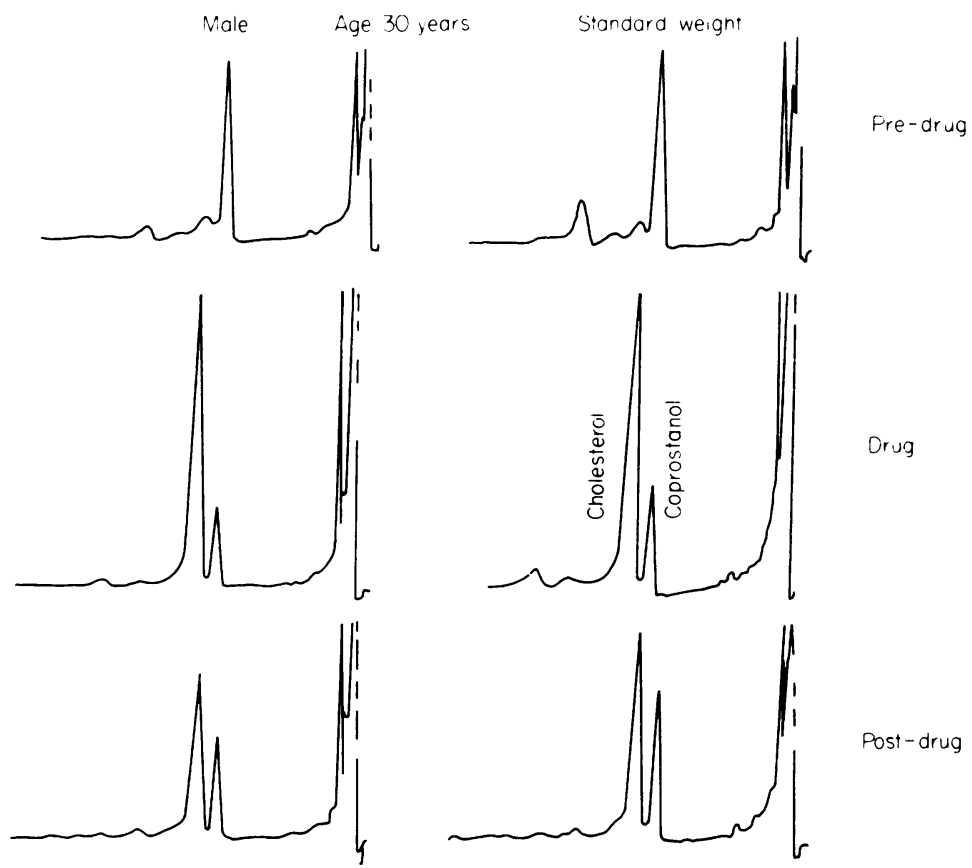

FIG. 5. Gas-chromatographic separation of neutral sterols excreted by a subject without fenfluramine-induced diarrhoea. Coprostanol is the predominant faecal neutral sterol during the pre-drug period. Excretion of coprostanol decreases during the drug period and that of cholesterol increases instead. The altered pattern of excretion of neutral sterols also persists during the post-drug period.

Dannenburg, W.N. \& WARD, J.W. (1971) The inhibitory effect of fenfluramine on pancreatic lipase. Archives internationales de pharmacodynamie et de thérapie, 191, 58.

Duhault, J. \& Verdavainne, C. (1967) Pharmacology and biochemistry of fenfluramine. Archives internationales de pharmacodynamie et de thérapie, 170, 276.

Eneroth, P., Hellstrom, K. \& Ryhage, R. (1964) Identification of neutral faecal steroids by GLC and MS: Studies of human excretion during two dietary regimens. Journal of Lipid Research, 5, 245.

Eneroth, P., Hellstrom, K. \& Sjovall, J. (1968) A method for quantitative determination of bile acids in human faeces. Acta chemica scandinavica, 22, 1729.

Evans, E., Miller, D.S., Samuel, P.D. \& Burland, W.L. (1975) The effects of fenfluramine and 780SE on fat absorption. Postgraduate Medical Journal, 51 (Suppl. 1), 115.

EVRARD, E.R. \& JANSSEN, G. (1968) GLC of human faecal bile acids. Journal of Lipid Research, 9, 226.

Garattini, S. (1971) Pharmacological studies on fenfluramine. South African Medical Journal, 45 (Suppl. 1), 13.

Hill, M.J. \& DraSAR, B.S. (1968) Degradation of bile salts by human intestinal bacteria. Gut, 9, 22 .

Hollingsworth, D.R. \& Amatruda, T.A. (1969) Toxic and therapeutic effects of EMTP in obesity. Clinical Pharmacology and Therapeutics, 10, 540.

HuANG, C.T.L. \& Nichols, B.L. (1975) New solvent system for the separation of free and conjugated bile acids. Journal of Chromatography, 109, 427.

Kirwan, W.O., Smith, A.N., Mitchell, W.D., Diane FAlCONER, J. \& EASTwOOD, M.A. (1975) Bile acid and colonic motility in rabbit and the human. Gut, 16, 894.

Le Douarec, J.C. \& Niven, C.E. (1970) Pharmacology and Biochemistry of Fenfluramine. Amphetumines and Related Compounds (Ed. by Costa, E. \& Garattini, S.). Raven Press, New York.
Meinoff, W.E. \& KeRN, F. (1968) Bile salt malabsorption in regional ileitis, ileal resection and manitol-induced diarrhoea. Journal of Clinical Investigation, 47, 261.

Mekhjian, H.S., Phillips, S.F. \& Hofmann, A.F. (1971) Colonic secretion of water and electrolytes induced by bile acids: Perfusion studies in man. Journal of Clinical Investigation, 50, 1569.

Miettinen, T.A. (1971) Cholesterol production in obesity. Circulation, 44, 842.

Miettinen, T.A. (1973) Catabolism of cholesterol via bile acids. In: The Bile Acids (Ed. by Nair, P.P. \& Kritchevsky, D.). vol. 2, p. 199. Plenum Press, New York.

Mitchell, W.D. \& Eastwood, M.A. (1972) Faecal bile acids and neutral steroids in patients with ileal dysfunction. Scandinavian Journal of Gastroenterology, 7, 29.

Munro, J.F., Seaton, D.A. \& Duncan, L.J.P. (1966) Treatment of refractory obesity. British Medical Journal, 2, 264.

Nestel, P.J. \& Hunter, J.D. (1974) Differences in bile acid excretion in subjects with hypercholesterolaemia, hypertriglyceridaemia and overweight. Australian and New Zealand Journal of Medicine, 4, 491.

PAWAN, G.L.S. (1969) Effect of fenfluramine on blood lipids. Lancet, i, 498.

Rubulis, A., Rubert, M.\& Faloon, W.W. (1970) Cholesterol lowering, fecal bile acids and sterol changes during neomycin and colchicine. American Journal of Clinical Nutrition, 23, 1251.

SEDGWICK, J.P. (1972) Fenfluramine in the treatment of obesity. International Symposium on Fenfluramine, Montreal, Jan. 19-21.

Statistical Bulletin (1959) New weight standards for men and women. Metropolitan Life Ins. Co., 40, 1. 
Tomlinson, S.A., Lines, J.G. \& Greenfield, M.A.M. (1975) The effect of fenfluramine on obesity and plasma lipids of patients with renal allografts. Postgraduate Medical Journal, 51 (Suppl. 1), 166.

TURTLE, J.R. (1972) Management of hyperglycaemia with fenfluramine. International Symposium on Fenfluramine,
Montreal, Jan. 19-21.

VAN DE KAMER, J.H. Huinink, H. \& WeiJers, H.A. (1949) Rapid method for faecal fat. Journal of Biological Chemistry, 177, 347.

Weijers, H.A. \& VAN de Kamer, J.H. (1953) Faecal fat. Acta paediatrica. Stockholm, Uppsala,. 42, 24. 